\title{
Inspección y rehabilitación de puentes atirantados en la red de carreteras del estado
}

\section{Inspection and Rehabilitation of Cable-Stayed Bridges in the State Highway Network}

\author{
Álvaro Navareño Rojo ${ }^{\mathrm{a}}$, Emilio Criado Morán ${ }^{\mathrm{b}}$ \\ ${ }^{a}$ Dr. Ingeniero de Caminos, Canales y Puertos, Subdirector General de Conservación, \\ Ministerio de Transportes, Movilidad y Agenda Urbana. \\ ${ }^{b}$ Ingeniero de Materiales, Jefe de Servicio, Ministerio de Transportes, Movilidad y Agenda Urbana
}

Recibido el 14 de octubre de 2020; aceptado el 19 de febrero de 2021

\section{RESUMEN}

En este artículo se describe la experiencia de los últimos años en la inspección y la ejecución de obras de rehabilitación de puentes atirantados pertenecientes a la Red de Carreteras del Estado (RCE), que gestiona directamente la Dirección General de Carreteras (DGC) dependiente del Ministerio de Transportes, Movilidad y Agenda Urbana (MITMA).

Durante los últimos años la Dirección General de Carreteras ha promovido la realización de numerosas inspecciones de puentes en su red de carreteras. Gracias a estas inspecciones se han podido detectar deterioros significativos en cuatro de sus puentes atirantados más antiguos: el puente de Amposta, el puente de Fernando Reig en Alcoy, el puente del Centenario en Sevilla y el Puente Internacional sobre el río Guadiana, en Ayamonte. Esta detección precoz ha permitido realizar o proyectar en dichas estructuras las actuaciones de rehabilitación y sustitución de tirantes necesarias para garantizar la seguridad de los usuarios.

Por lo tanto, es necesario destacar la importancia de realizar inspecciones especiales en los puentes atirantados construidos en España, ya que algunos de ellos van alcanzando sus primeros 30-40 años de vida útil, y poder detectar la necesidad de reemplazar o sustituir algunos de sus elementos más vulnerables, como puede ser el sistema de atirantamiento.

PALABRAS ClAVE: Sistema de atirantamiento, inspección de puentes, vida útil, conservación, sustitución.

(C) 2021 Asociación Española de Ingeniería Estructural (ACHE). Publicado por Cinter Divulgación Técnica S.L. Todos los derechos reservados.

\section{ABSTRACT}

This article describes the experience of recent years in the inspection and the rehabilitation on cable-stayed bridges belonging to the State Roads Network, which is directly managed by the General Directorate of Roads under the Ministry of Transport.

In recent years, the General Directorate of Roads has promoted the performance of numerous inspections of bridges in its road network. Thanks to these inspections, it was possible to detect significant deterioration in four of its oldest cable-stayed bridges: the Amposta bridge, the Fernando Reig bridge, in Alcoy, the Centenario bridge in Seville and the international bridge over the Guadiana river, in Ayamonte. This early detection has made it possible to carry out or project, in said structures, the actions of rehabilitation and replacement of cable stay necessary to guarantee the safety of users.

Therefore, it is necessary to highlight the importance of carrying out special inspections on cable-stayed bridges built in Spain, as some of them are reaching their first 30-40 years of service life; in order to detect the need to replace or substitute some of its most vulnerable elements, such as the cable stay system.

KEYWORDS: Cable-stayed system, bridges inspection, life cycle, maintenance, replacement.

(C) 2021 Asociación Española de Ingeniería Estructural (ACHE). Published by Cinter Divulgación Técnica S.L. All rights reserved.

* Persona de contacto / Corresponding author:

Correo-e / email: anavareno@mitma.es (Álvaro Navareño Rojo).

Cómo citar este artículo: Navareño Rojo, A., Criado Morán, E., (2021) Inspección y rehabilitación de puentes atirantados en la red de carreteras del estado, Hormigón y Acero, 72(294-295), 163-175, https://doi.org/10.33586/hya.2021.3034 

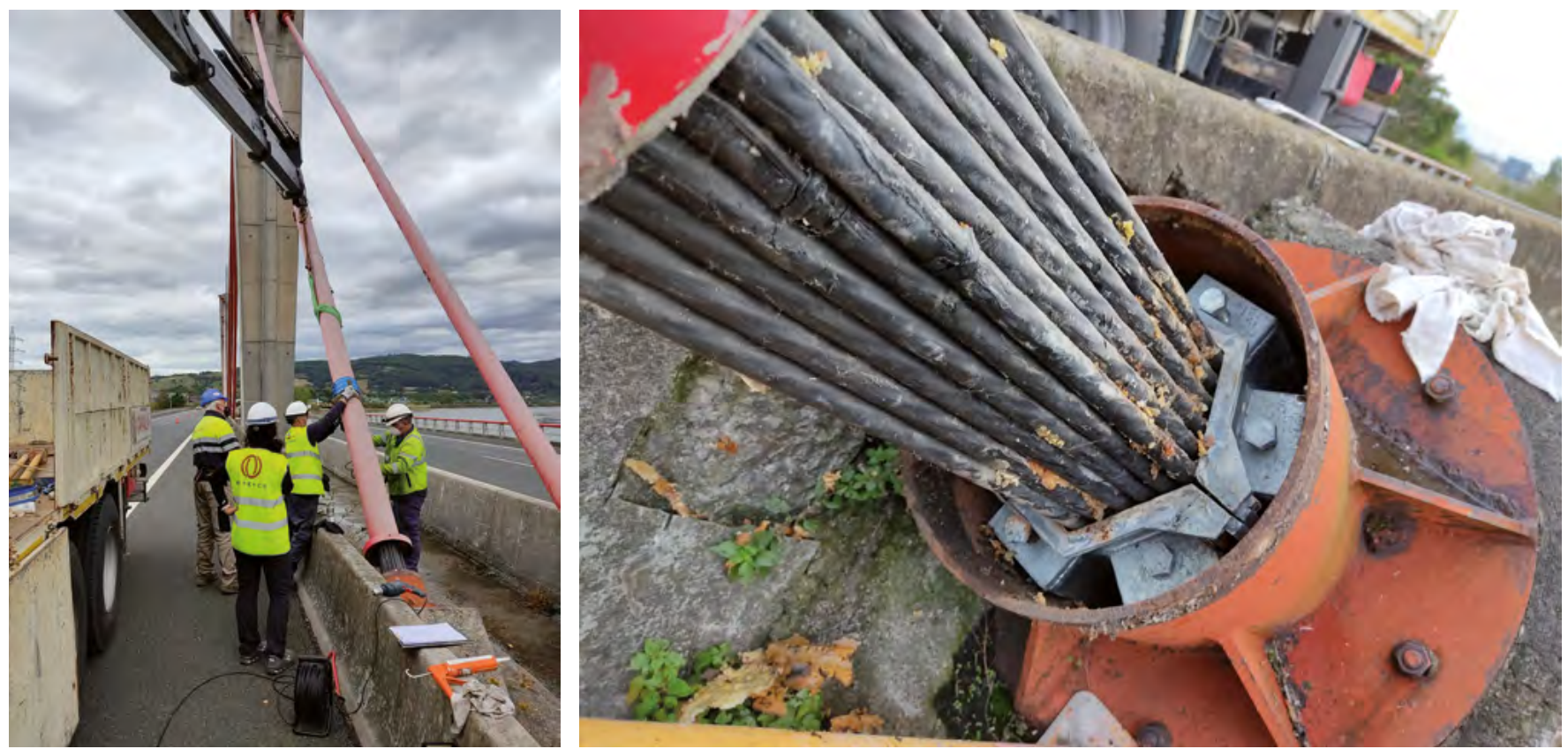

Figura 1. Inspección especial, octubre de 2020, del atirantamiento del puente de Colindres en la A-8.

1.

\section{INTRODUCCIÓN}

En el S. XIX, en España, pudieron verse ejemplos de puentes colgantes-atirantados importantes. Tal es el caso del famoso puente "colgante" de Mengibar (Jaén), sobre el río Guadalquivir, inaugurado en 1843 y que prestó servicio durante 87 años, hasta 1930-32, fecha en que fue sustituido por otro de distinta tipología. Posteriormente, ya en el siglo XX, se construyó el soberbio puente "colgante" de Amposta de 1921, aún en servicio y que luego citaremos; pero no fue hasta la segunda mitad del siglo pasado cuando la construcción de puentes de esta tipología experimentó un gran desarrollo. En la década de los años 50 se construyeron las primeras autopistas en España. La primera fue la Madrid-Barajas en 1952, para dar respuesta al extraordinario incremento del parque de automóviles y camiones. Entre 1950 y 1970 el número de turismos se multiplicó casi por 20 [1].

Este hecho propició la construcción de importantes puentes de carretera, que junto al desarrollo de nuevas técnicas constructivas y al mejor conocimiento del comportamiento de los materiales permitió construir puentes singulares con luces muy superiores a las de las épocas previas. Destacan entre ellos los puentes atirantados, con técnicas similares a la actual, que recogían los sistemas de pretensado desarrollados a lo largo del siglo XX. El primer puente en España de este tipo es el de Sancho el Mayor, en Castejón, en la AP-15, de 1978 [2]. El siguiente es el puente de Rande, en Vigo, en la AP-9, también de 1978, y el tercero en antigüedad el del Ingeniero Carlos Fernández Casado sobre el embalse de Barrios de Luna (León), en la AP-66, de 1983.Los tres están gestionados por sociedades concesionarias de peaje.

En España dentro de la RCE no concesionada, se puede encontrar con esta tipología: el puente de Amposta ("colgante-atirantado", en la N-340a), el puente de Alcoy (en la N-340), el puente del Centenario (en la SE-30), el puente in- ternacional sobre el Guadiana (en la A-49), el puente de Colindres (en la A-8) (figura 1) el puente sobre el Iregua (en la LO-20) y el reciente puente de la Constitución de 1812 (en la CA-35). Además de tres pasarelas peatonales situadas sobre la M-40 y M-1 1 en Madrid, y sobre la A-68 en Zaragoza.

La mayoría de estos puentes supusieron un hito en el momento de su construcción, y por ello se disponen de una extensa bibliografía sobre la etapa inicial de cada obra. Pero donde existe un cierto vacío, aunque en los últimos años se ha paliado un poco, es en el conocimiento de lo que sucede con la estructura una vez construida.

Se puede afirmar que la sustitución de los cables en los puentes atirantados supone un reto técnico de primer orden. Ya se pueden encontrar en la bibliografía algunas experiencias publicadas sobre actuaciones de este tipo en diferentes partes del mundo.

Por este motivo, uno de los objetivos de este artículo es describir brevemente la experiencia de la Dirección General de Carreteras en la conservación de este tipo de estructuras, tanto en su inspección como en la rehabilitación, ya que al tratarse de una tarea compleja, heterogénea y poco amparada por las regulaciones existentes, las experiencias propias y ajenas suponen una gran ayuda.

2.

\section{PLANIFICACIÓN DEL MANTENIMIENTO}

Si nos remitimos, en una primera aproximación, al denominado concepto de "vida útil" de una estructura encontraremos el documento contenido en el "Eurocódigo EN-1990. Bases de cálculo de estructuras" [3] que establece la duración correspondiente a cada tipo estructural de referencia, tal como se indica en la tabla 1: 
TABLA 1.

Vida útil de las estructuras según Eurocódigo EN-1990 [3]

\begin{tabular}{ccl}
\hline & VIDA ÚTIL DE CÁLCULO INDICATIVA \\
\hline $\begin{array}{c}\text { Categoría de } \\
\text { vida útil de cálculo }\end{array}$ & $\begin{array}{c}\text { Vida útil de } \\
\text { cálculo indicatíva }\end{array}$ & \multicolumn{1}{c}{ ejemplos } \\
\hline 1 & 10 & $\begin{array}{l}\text { Estructuras temporales (1) } \\
\text { Partes de estructuras } \\
\text { reemplazables. Por ejemplo: } \\
\text { vigas de rodadura, o aparatos } \\
\text { de apoyo }\end{array}$ \\
3 & 10 a 50 & $\begin{array}{l}\text { Estructuras agrícolas } \\
\text { o similares }\end{array}$ \\
4 & 15 a 30 & $\begin{array}{l}\text { Estructuras de edificios y otras } \\
\text { estructuras comunes }\end{array}$ \\
5 & 50 & $\begin{array}{l}\text { Estructuras de edificios } \\
\text { monumentales, puentes y } \\
\text { otras estructuras de ingeniería } \\
\text { civil }\end{array}$ \\
\hline
\end{tabular}

(1) estructuras o partes de estructuras que puedan desmontarse con la intencion de volver a usarse no deberían considerarse como estructuras temporales.

Por otro lado, en la Instrucción de hormigón estructural "EHE08" [4] se dedica un capítulo al mantenimiento de las estructuras previendo, en su Art. $103^{\circ}$ que el autor del proyecto redacte un Plan de Mantenimiento específico, que constituirá un documento más del proyecto de la estructura en cuestión. Además de esto la EAE-10 [5] también recoge un capítulo dedicado al mantenimiento, indicando en su artículo 93 la obligatoriedad de incorporar un "plan de inspección y mantenimiento" en el proyecto de estructuras de clase 4 o 3 .

Quiere decir esto que las estructuras modernas, en concreto los puentes, se conciben para prestar un servicio limitado en el tiempo. Probablemente esto es así por el nivel tan avanzado de conocimientos que se tiene hoy en día, y la necesidad de optimización de los recursos disponibles, que siempre son limitados. Esto choca de pleno con la concepción de las estructuras en la antigüedad. Como por ejemplo ejemplo, la que tenía Caius lulius Lacer, constructor del puente de Alcántara, y que señaló sobre el mismo: "Pontem perpetui mansurum in saecula mundi" (el puente, destinado a durar por siempre en los siglos del mundo).

Esta ambición no se debe trasladar a los puentes contemporáneos y por este motivo, tal como recoge la normativa vigente, resulta tan importante la realización de inspecciones en las estructuras que permitan detectar deterioros o anomalías para que puedan subsanarse, lo antes posible, mediante las actuaciones de mantenimiento y rehabilitación.

Sin embargo, prácticamente todos los puentes construidos previamente a la entrada en vigor de las citadas regulaciones no disponen de plan de mantenimiento. De hecho, de los puentes que nos atañen en este artículo únicamente el puente de la Constitución de 1812 dispone realmente del mismo (aunque también existe un borrador de plan de mantenimiento del puente del Centenario de primeros del 2000).

Ante esta situación, son los propietarios de la infraestructura los que tienen que señalar las directrices de las actuaciones de conservación. Estas directrices suelen ser comunes para todos los puentes de la red gestionada, variando ligeramente en función de tamaños o tipologías, y cubren las necesidades de la gran mayoría de los puentes. Sin embargo, para los puentes atirantados son insuficientes y es necesario hacer inspecciones con mayor nivel de detalle.
3.

\section{INSPECCIONES DE PUENTES ATIRANTADOS}

Las inspecciones de puentes se pueden dividir en tres niveles.

Un primer nivel compuesto por inspecciones visuales llevadas a cabo por los equipos de conservación ordinaria que vigilan diariamente la carretera en la que se sitúa la estructura (básicas).

Un segundo nivel en el que estas inspecciones son realizadas por ingenieros especialistas con cierta frecuencia, aproximadamente cada 5 años (principales). En este ámbito, la aparición de los llamados "drones" proporciona una importante economía de costes en la inspección, a la vez que abre un mundo de posibilidades para desarrollar una inspección completa.

En general estas inspecciones, en los puentes atirantados, son válidas para al tablero y los pilonos, donde pueden ser representativas. Sin embargo, no aportan suficiente información del sistema de atirantamiento, característico de este tipo de obras.

Por ello, es necesario un tercer nivel formado por inspecciones especiales mediante medios auxiliares y ensayos de caracterización. Si bien en puentes convencionales las inspecciones especiales pueden no ser necesarias (si no presentan patologías asociadas), en los puentes atirantados son obligadas para poder conocer el estado del sistema de atirantamiento, como hemos citado. La periodicidad de dichas inspecciones, para puentes atirantados, puede variar generalmente según los distintos elementos del puente, entre los 5 y los 10 años, según se detalla en el apartado 6 de este artículo.

Por otro lado, hay que destacar también las posibilidades, dentro del proceso de digitalización de la sociedad en el que vivimos, de la monitorización en continuo de algunos de los parámetros estructurales del puente. Este aspecto es muy importante para tener un control de muchos elementos y poder obtener el comportamiento global, en este tipo de obras tan singulares.

\section{4. \\ INSPECCIONES ESPECIALES}

Dada la especial importancia que tienen las inspecciones especiales en los puentes atirantados, especialmente en el sistema de atirantamiento, a continuación se describirán las consideraciones que hay que tener en cuenta a la hora de inspeccionar estos elementos.

Los puntos principales del sistema a comprobar en cualquier inspección son [6]:

- Anclajes de los tirantes en el tablero y en los pilonos.

- Dispositivos amortiguadores.

- Longitud libre de tirantes.

\subsection{Anclaje de tirantes en el tablero o pilonos.}

Los anclajes son unos de los puntos más críticos de estas estructuras. Las principales inspecciones a realizar en los mismos son las siguientes: 


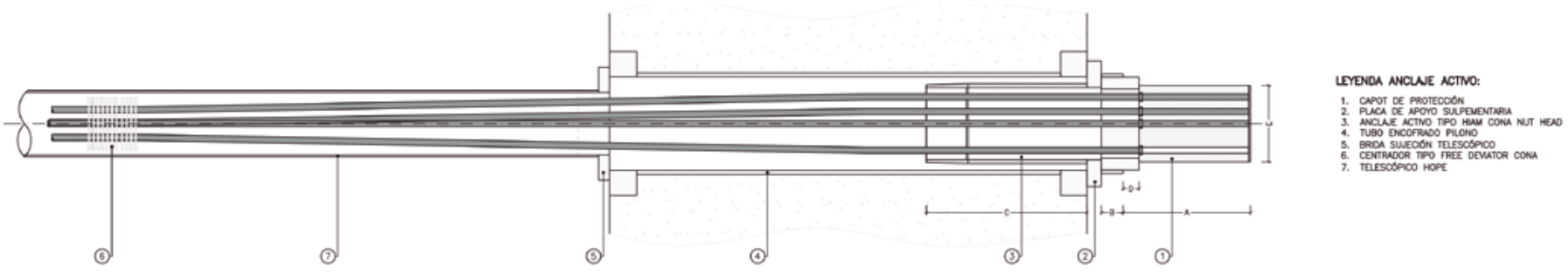

PLANTA ANCLANE ACTNO

Figura 2. Croquis de anclaje pasivo.

a) Inspección exterior del anclaje: Consiste en llevar a cabo la inspección visual, con personal no especializado, en la que se examinan los componentes exteriores del anclaje: capot, tubo de regulación o placa de apoyo, y tuerca, comprobando la protección anticorrosiva, tornillos, drenaje y cualquier signo de fuga de cera. Si se observa un daño o abolladura en la cara externa del capot, es necesaria una inspección interna. Una vez finalizada, según el tipo de anclaje se pulveriza una película de grasa mineral sólida o una emulsión de cera sobre las roscas a vista.

b) Inspección interior del anclaje: En esta inspección, con personal especializado, se comprueba el relleno de cera, la protección anticorrosiva del capot, el anclaje y la condición de los cordones y de las cuñas. Para esto último, si es necesario, se retira la cera de algunos cordones periféricos (\% superiores y \% inferiores). Después de la inspección es necesario rellenar de cera por gravedad y pulverizar una película de grasa mineral sólida o una emulsión de cera sobre las roscas a vista. También se debe recomponer el nivel de protección de los elementos (pintura, sustitución de tornillería dañada, sellados y juntas).

c) Inspección simplificada de los tubos de acero y placas inferiores (o zonas de salida de tirantes en pilonos desde el exterior): Esta es una inspección sencilla y visual que puede llevarse a cabo por un equipo no especializado. Se examina la placa de apoyo, el cajón de anclaje, el tubo guía y el tubo antivandálico de acero galvanizado. Los principales aspectos a chequear son la protección anticorrosiva, presencia de los tornillos, estado de la galvanización o pintura, posibles daños en la soldadura (fisuras) y drenaje del tubo inferior. También es necesario verificar el estado de la junta de cubrición de la unión entre vaina y tubo antivandálico (en anclaje de tablero).

d) Inspección detallada de los tubos (o zona exterior de pilono): Es una inspección acompañada de unas tareas de mantenimiento preventivo que deberá llevarse a cabo por un equipo especializado. Tiene por objeto, además de todas las tareas descritas en el apartado anterior, verificar el par de apriete de los tornillos y recomponer el nivel de protección de los elementos (pintura, sustitución de tornillería dañada, sellados y juntas). O bien, en el caso de anclaje del pilono, revisión de los elementos menos accesibles del pilono mediante medios auxiliares que permitan acceder a ellos para poder observar de cerca su estado.

\subsection{Dispositivos amortiguadores (externos al tirante o in- ternos)}

Los dispositivos amortiguadores presentan algunos elementos susceptibles de ser sustituidos, por lo que es necesario prestar especial atención a los mismos.

a) Inspección externa de los dispositivos amortiguadores de tirantes: Se realiza una inspección visual por personal no especializado para comprobar el correcto estado de los componentes externos del amortiguador. Se comprueba la protección anticorrosiva, tornillos y cualquier signo de daño de los dispositivos hidráulicos (manchas en el suelo).

b) Inspección interna y detallada de los dispositivos amortiguadores de tirantes: Para inspeccionar el amortiguador, comprobaremos el aspecto general de todos los componentes. Tras haber levantado el tubo antivandálico, se verifica la protección anticorrosiva de los componentes, el correcto apriete del collar sobre el haz de cordones, el correcto apriete de los topes de pistón contra la pared del tubo guía calibrado y comprobar cualquier fuga de aceite de la cámara.

\subsection{Longitud libre de tirantes}

La inspección de la longitud libre de tirantes depende en gran medida de la tipología del tirante y su principal dificultad es el acceso a los componentes de los mismos.

Si los tirantes llevan una vaina de protección, este elemento es el único visible, por lo que se podrán observar grietas, roturas y otros defectos en la vaina, pero no se podrán atribuir deterioros directamente a los cordones.

La inspección visual puede ser realizada desde el tablero o el pilono, pero a partir de una determinada altura o distancia, incluso con el uso de prismáticos, los pequeños deterioros no suelen ser visibles, por lo que hay que recurrir al uso de drones, $\mathrm{u}$ otros medios de acceso.

En el caso más complejo, que es el de los tirantes con cables protegidos con inyección de lechada, es necesario recurrir a ensayos no destructivos. Además de los clásicos ensayos de cuerda vibrante que nos dan el valor tensional del conjunto del tirante, para determinar si la lechada está protegiendo los cables a lo largo de toda su longitud, se puede realizar una inspección mediante "sonda capacitiva" [7].

El método de inspección por sonda capacitiva se centra principalmente en la detección de oquedades en vainas de polietileno (o polipropileno) inyectadas con lechada de cemento 
o similar. La durabilidad de este tipo de tirantes se ve condicionada por el proceso de inyección de la vaina y las zonas de anclaje, así como por la calidad del producto inyectado. La similitud de estos tirantes con los tendones de pretensado exterior implica que se pueden observar los mismos defectos, como son las inyecciones incompletas o la presencia de lechada de insuficiente calidad, generalmente en "puntos altos" del tirante. Este método también permite detectar, además de las oquedades en el interior de una vaina de plástico, la presencia de acero, agua o "pasta blanca".

El proceso consiste en desplazar la sonda siguiendo la generatriz superior del tirante (las bolsas de aire suelen encontrarse en esa zona). En tiempo real, se visualiza la evolución de la señal; cuando se detecta un posible defecto, se realiza una rotación alrededor de la vaina para obtener una imagen de la sección completa del tirante. Es por tanto un procedimiento relativamente manual, en fase de automatización.

Finalmente, en el mercado existen algunos otros métodos de inspección para evaluar el estado de los tirantes, más o menos eficaces según lo que se quiera determinar. Se han desarrollado en diversas publicaciones [8], [9], entre las cuales puede destacarse el Manual de Tirantes [9].

5.

\section{ACTUACIONES DE REPARACIÓN O REHABILITACIÓN DE PUENTES ATIRANTADOS}

Los puentes atirantados requieren de actuaciones de reparación o rehabilitación que en gran parte son similares a las del resto de los puentes, ya que muchos de los elementos son comunes. Sin embargo, estos puentes presentan unos elementos muy característicos, como son los sistemas de sustentación mediante cables o tirantes que requieren de actuaciones muy diferentes a las que se realizan habitualmente. Por este motivo, en este apartado se van a describir las actuaciones de reparación o sustitución que se han llevado a cabo en cuatro de los puentes atirantados cuya gestión depende directamente de la DGC, curiosamente en los 4 puentes de esta tipología más antiguos.

\subsection{Puente "colgante" de Amposta}

El puente de Amposta fue un proyecto de Eugenio de Ribera; se inauguró en 1921 [10] y está situado en el PK 1082,300 de la carretera N-340a. Supuso un hito para la época, ya que se trataba de una estructura de un solo vano de $134 \mathrm{~m}$ de luz que se encontraba suspendido (en este caso suspendido y atirantado) de un sistema de cables. El puente fue destruido en la Guerra Civil y reconstruido en 1941, aunque no fue la única actuación de conservación que se ha llevado a cabo sobre él, ya que en 1972 se realizó una importante obra de reparación en la que se sustituyeron algunos cables y péndolas. Ya en 2008 se realizó una rehabilitación integral del puente, que se describirá más adelante. Es importante señalar que el puente, que ha cumplido hace poco con los cien años en los que se estima la vida útil de los puentes actualmente, ha requerido de actuaciones significativas cada treinta años aproximadamente (figura 3)

El sistema de suspensión del tablero combina las técnicas empleadas tanto en los puentes atirantados como en los colgantes. Es un ejemplar de puente muy singular por tanto, por la antigüedad de su concepción y por sus elementos tan caracte-

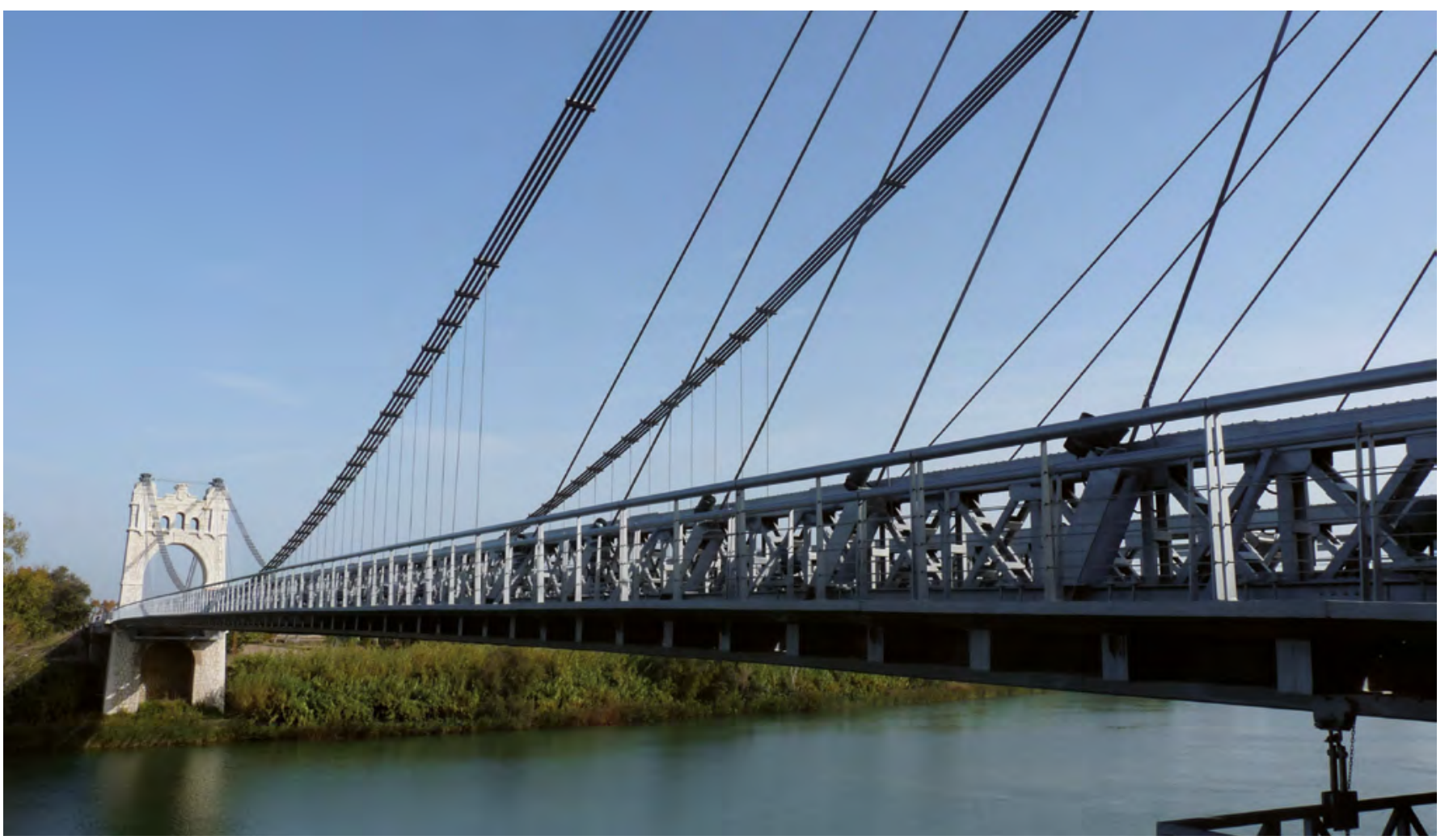

Figura 3. Vista longitudinal del puente de Amposta rehabilitado. 

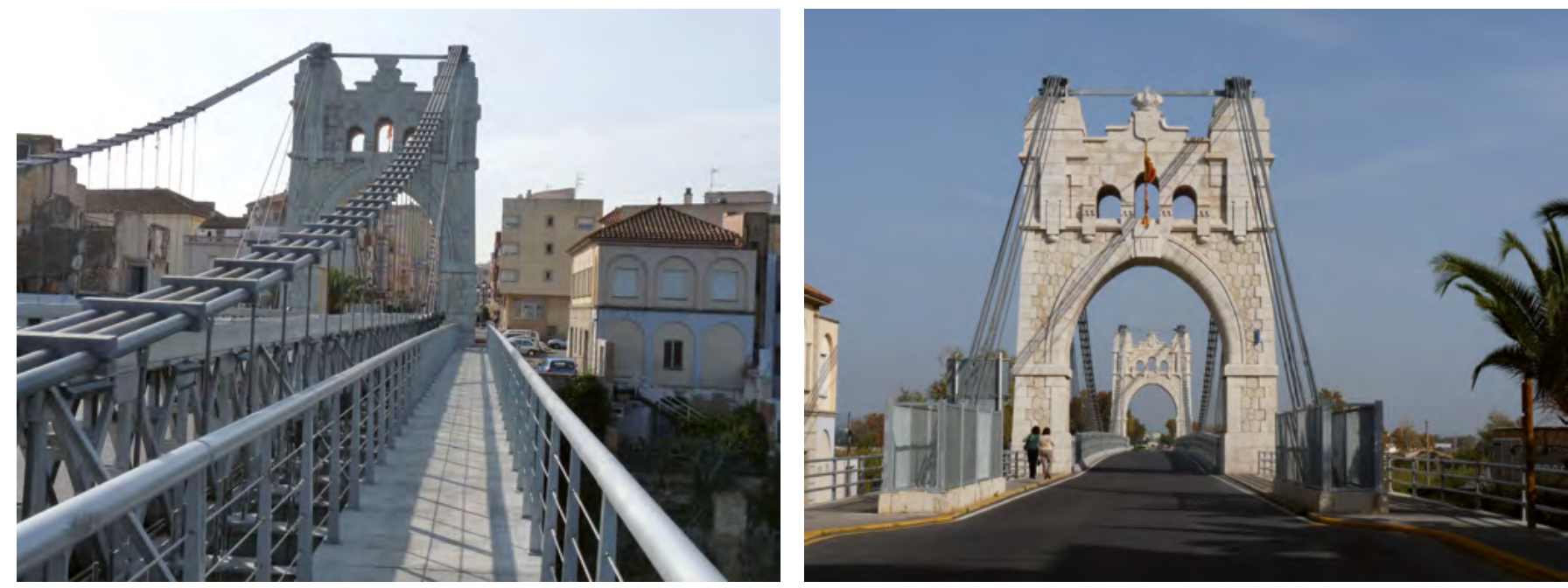

Figura 4. Detalle de cables principales, con elementos de union a las pendolas en puente rehabilitado. Imagen del pilono de fábrica (derecha)y de los tirantes en vanos extremos (izquierda).

rísticos, que han podido mantenerse hasta hoy día, en servicio. Posee, por tanto, un valor patrimonial innegable que va mucho más allá de su funcionalidad.

El sistema de sustentación principal está constituido por un total $8+8$ cables que recorren toda la estructura, pasando por encima de los pilonos (silla), y se anclan al terreno (macizo de anclaje) cerca del estribo, en el exterior de la estructura. Antes de 2008, los cables principales no eran todos de la misma época; 13 provenían de la reconstrucción después de la guerra y 3 fueron colocados durante la reparación efectuada en el año 1972 (figura 4).

Lo mismo sucedía con las 146 péndolas en las que se sustenta la zona central del tablero, conectadas a los cables principales mediante un elemento singular llamado "percha"; existían tres tipos de péndolas: nuevas con cable (52), nuevas sin cable (18) y antiguas (76) existentes antes de la reparación de 1972.

Además de las péndolas, los tramos del vano central más próximos a los pilonos están suspendidos de un total de 24 tirantes, cuya trayectoria es la siguiente: un extremo se ancla en el tablero, sube hasta el pilono donde rodea una polea, para volver a descender hasta el tablero y anclarse al mismo en su otro extremo. Los cables que formaban los tirantes inclinados estaban constituidos por cordones trenzados de acero galvanizado (año 1972), de un diámetro de $40 \mathrm{~mm}$, con alambres de $3 \mathrm{~mm}$ de diámetro.

Finalmente, para los dos vanos extremos, otros cuatro cables (cables de retenida) parten de la silla situada en cada pilono hacia el macizo de anclaje; su misión es compensar los esfuerzos horizontales. Tanto los cables principales como los tirantes de retenida se anclan de forma similar en el macizo de anclaje.

Dentro de las actividades llevadas a cabo dentro del sistema de gestión de puentes de la DGC, en el año 2004 se realizó una inspección especial en la que se pudo comprobar el mal estado debido a la corrosión de gran parte de los elementos metálicos de sustentación.

En este caso la detección de estos desperfectos fue relativamente sencilla, ya que la mayoría de los elementos eran visibles a simple vista o con pequeños medios auxiliares.
En el año 2008 se realizó la obra de reparación de la estructura que, en el caso de los elementos de sustentación, supuso la completa sustitución de los mismos.

Para la ejecución de la obra se cortó el puente al tráfico, lo que permitió mantener las cargas de peso propio del puente con cuatro de los ocho cables de cada margen, de tal manera que se pudieron sustituir los cuatro cables restantes, pasar la carga a los mismos y posteriormente sustituir los otros cuatro.

\subsection{Puente atirantado de Alcoy}

El puente lleva el nombre de Fernando Reig (Vilaplana), insigne ingeniero alcoyano. Está situado en el p.k. 794,000 de la carretera N-340 en Alcoy (Alicante) y constituye un ejemplar singular dentro del conjunto de obras de paso de la Red de Carreteras del Estado. Su proyecto y construcción incorporaron una solución innovadora de tablero completamente prefabricado a base de piezas de pesos convencionales, con la idea de que la industrialización de los tableros pudiera extenderse a luces cada vez mayores como la de este puente, que alcanza los $273 \mathrm{~m}$. En el momento de su ejecución fue el de mayor luz con tablero prefabricado del mundo. Fue inaugurado en abril de 1987.

En el año 2015 se realizó una inspección especial (anteriormente se habían realizado ya otras inspecciones, además de un ensayo dinámico) en la que se detectan una serie de desperfectos en los sistemas de contención e impostas. Esto, sin suponer un riesgo estructural para el puente, sí podía representar afecciones graves para los usuarios que pasaban bajo la estructura, en la zona del barranco del río Barxell, por lo que se programó una actuación de emergencia que comenzó en noviembre de 2015.

En dicha inspección únicamente se detectaron desperfectos menores en las protecciones exteriores de algunos de los tirantes. Se analizó también la documentación existente del puente. Por lo demás, al no detectarse comportamiento anómalo de la estructura, no se contemplaron actuaciones sobre los tirantes más allá de la reparación de los deterioros locales detectados. 
Sin embargo, durante los trabajos de hormigonado del zócalo de anclaje del nuevo pretil, se produjo una rotura súbita en el interior de un tirante, que quedó relatada de la siguiente manera en los informes posteriores [11]:

"El pasado jueves 28 de julio, durante la realización de los trabajos de hormigonado de aceras e imposta cerca de la pila, en el lado norte del tablero, se advirtió un comportamiento anómalo en el tirante designado como T-41 en los planos de proyecto.

Este comportamiento anómalo tiene que ver con el incidente ocurrido la mañana del 28 de julio en el que, según manifestaciones del personal presente en obra esa mañana, "habia habido un ruido e inmediatamente después el puente se habia movido como si hubiera habido un terremoto", y, además, "el puente habia bajado". El tirante en cuestión es el tirante del vano Alcoy más próximo a la pila, en el lado norte del tablero. El descenso pudo cuantificarse en torno a unos $2 \mathrm{~cm}$."

A partir de ese momento se cortó la circulación en el puente y comenzó una inspección exhaustiva de los tirantes. El primer paso, tras diversas reflexiones y revisiones de los anclajes al tablero de varios tirantes cercanos, fue desmontar el tirante más cercano al lugar del incidente. En este caso el sistema de tirantes estaba formado por cables sin autoprotección recubiertos de una lechada protectora y protegidos por una vaina externa de polietileno. Tras desmontar el tirante al retirar la vaina, se comprobó que una sección del tirante en la parte superior del mismo, cercana a su anclaje en el pilono, no contaba con lechada protectora. Este hecho habría generado un proceso de corrosión de los cables que, sin la lechada, no contaban con protección de tal manera que 15 de los 28 cables habían perdido su sección completamente y los 13 restantes, que rompieron en el último momento, también contaban con una sección reducida (figura 5). Así mismo se solicitó un informe a la UPM, sobre aspectos químicos (de caracterización de distintas zonas de la lechada protectora) y físicos (sobre el proceso de corrosión acaecido en los cables). Las conclusiones bien podrían ser objeto de otro interesante artículo.

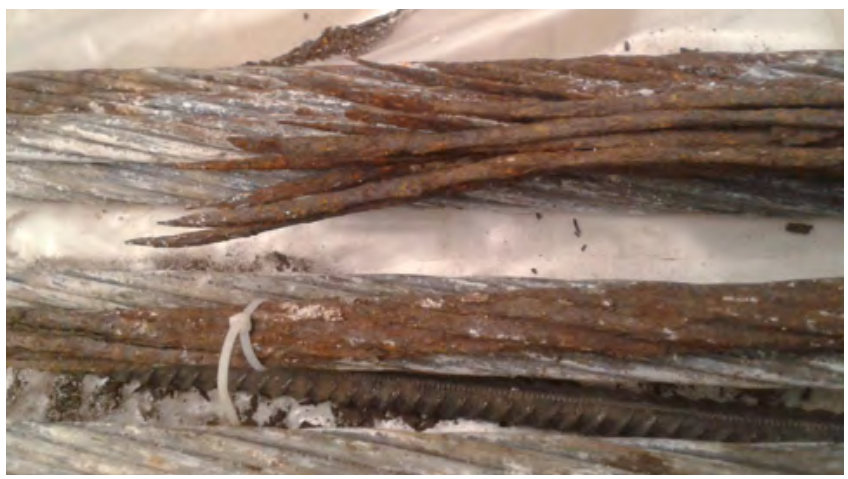

Figura 5. Detalle de cables de acero corroídos en tirante roto, en zona sin protección de lechada.

A partir de ese momento se planteó la necesidad de comprobar el estado del resto de los tirantes, si bien la presencia de la vaina de polietileno y la lechada dificultaban cualquier tipo de inspección visual. Se analizaron diferentes métodos de ensayos no destructivos (figura 6), y finalmente se optó por utilizar una sonda capacitiva que recorría todo el tirante, ya que es el único método viable que permite conocer si bajo la vaina existen huecos por falta de lechada como el que originó el incidente. Sin embargo, existía una zona crítica no inspeccionable mediante este método, la zona del tirante dentro del pilono antes de su anclaje superior, debido a la imposibilidad física de acceder con la sonda a la zona afectada.

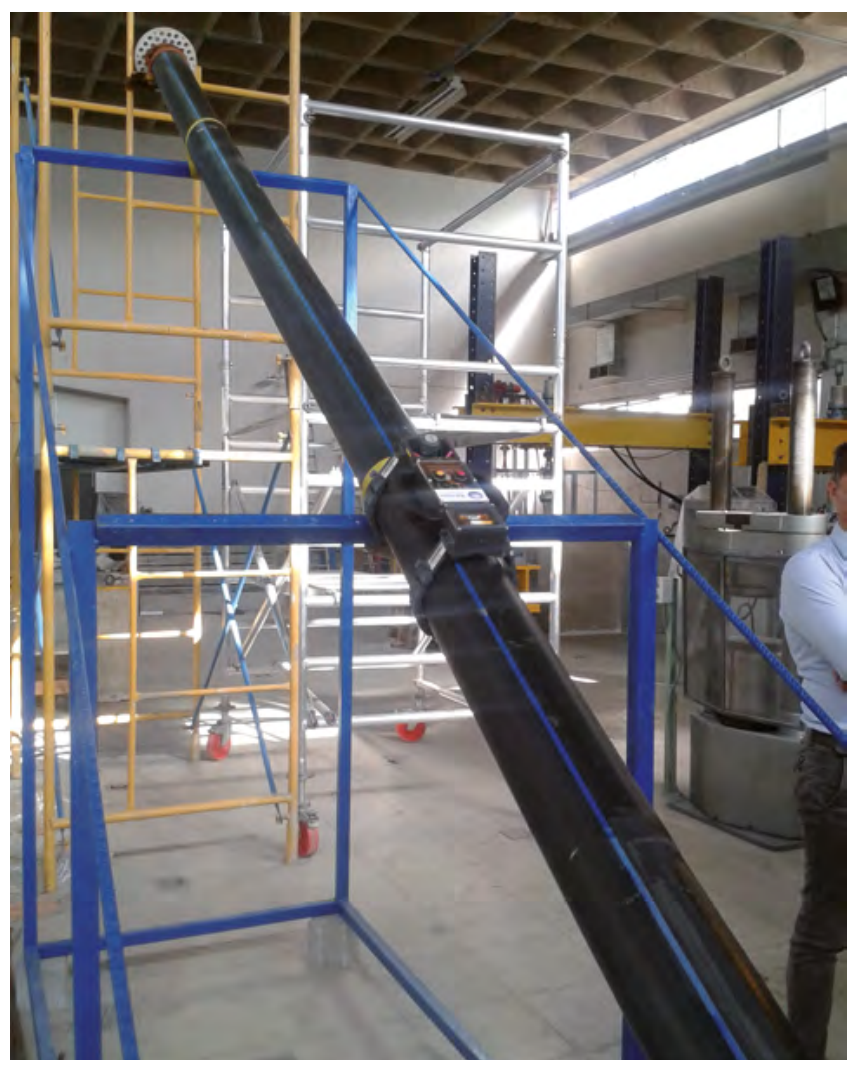

Figura 6. Ensayo de calibracion de "sonda capacitiva" en un tirante de prueba montado en laboratorio.

Es importante señalar que cuando existen sospechas de que la capacidad estructural de un cable de pretensado está comprometida, no se puede cortar la vaina, ya que el fallo del pretensado puede haber hecho que la vaina adquiera carga tensional. En ese caso la rotura de la misma podría desencadenar la rotura del cable, con el consiguiente efecto látigo y peligro para los operadores.

Una vez auscultados todos los tirantes se comprobó que existían zonas con deterioros, no tan importantes como el del tirante roto, a priori, pero que iban a seguir evolucionando con el tiempo. Estos hechos junto con la imposibilidad de auscultar los tramos de los tirantes por el interior del pilono y los antecedentes existentes, justificaron la decisión final de sustituir el resto de tirantes del puente.

La obra de cambio de tirantes no fue sencilla. El principal problema fue el desconocimiento de la capacidad de carga real de los tirantes, ya que no se podía garantizar que no existieran secciones de tirantes muy debilitadas en el tramo que no se había podido auscultar. En condiciones normales se puede retirar un tirante, ya que la carga que soporta el mismo puede ser absorbida por los adyacentes, pero en este caso la falta de garantía sobre la capacidad de los tirantes de aguantar esa sobrecarga, hizo necesario tomar medidas de seguridad adicionales, como el apeo de varios tramos de la estructura (figura 7). 

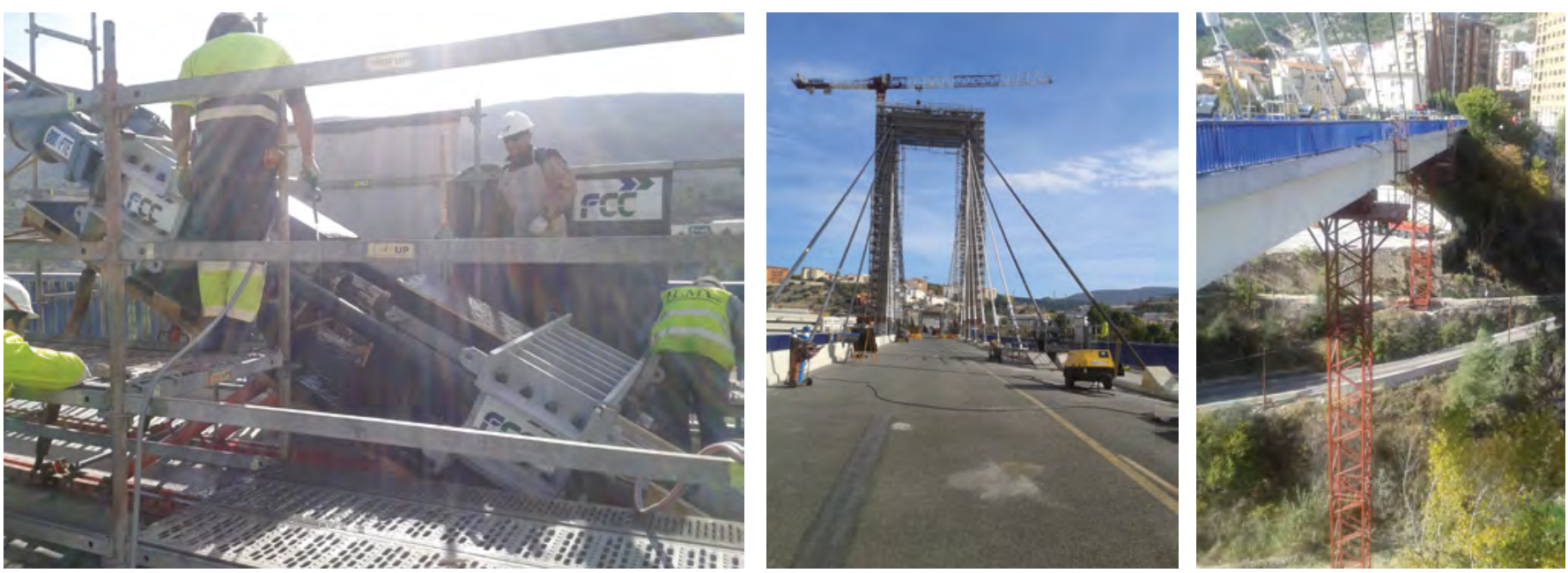

Figura 7. Puente atirantado de Alcoy. Plataforma de tablero en obras (izquierda). Torres de apeo de tablero (centro). Detalle del sistema (by-pass metálico) de corte y destesado controlado de tirantes (derecha).
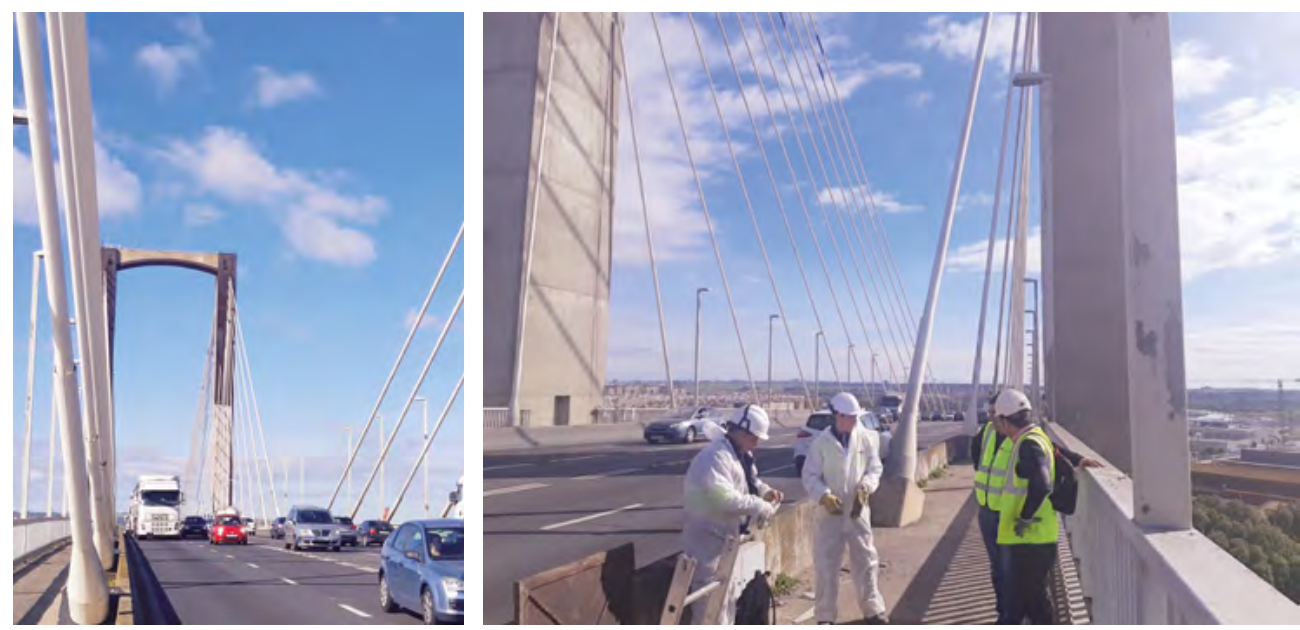

Figura 8. Detalle puente atirantado del Centenario (izquierda). Acceso para inspeccion del interior del tablero (derecha).

Una incidencia importante que surgió fue la escasa longitud libre de los cables situados detrás de las cuñas de anclaje. Este hecho impedía destesar los cables mediante gatos en la cabeza de los pilonos, que es el proceso más habitual. En su lugar, se concibió un sistema auxiliar para destesar una parte del tirante en su zona inferior que permitiese el corte de los cables sin tensión.

Otro aspecto singular fue el proceso de desmontaje a seguir [12]. Para evitar la sobrecarga de los tirantes, una vez apeado el puente, se procedió al desmontaje de los tirantes que se encontraban sobre los apeos. Al estar coartado el desplazamiento vertical del tablero en estos puntos, la carga de los tirantes desmontados no se transmitía a los tirantes contiguos sino a las torres de apeo.

Una vez desmontados los tirantes apeados (T33, T36, T39, T42, T45, T48 y T51), que estuvieron desmontados hasta el final del proceso constructivo, se procedió al desmontaje y sustitución de los tirantes intermedios citados (entre torres de apeo), por parejas, para evitar desequilibrios en el pilono. Antes de proceder a desmontar la siguiente pareja se instalaban los desmontados. De esta forma, siempre había como máximo una pareja de tirantes desmontados sin apear.
Una vez sustituidos todos los tirantes intermedios, se procedió a montar los nuevos tirantes ubicados sobre los apeos. Por último, se retiraron los apeos del puente, para restablecer la geometría original.

Finalmente, tras la ejecución de las obras, que duraron dieciocho meses, se volvió a poner el puente en servicio con total garantía de seguridad durante un periodo que se espera pueda rondar 100 años.

\subsection{Puente atirantado del Centenario en Sevilla}

El puente del Centenario (figura 8) permite cruzar por la autovía de circunvalación SE-30 sobre la dársena del río Guadalquivir. Se puso en servicio en el año 1992. A raíz de los hechos acontecidos en el puente de Alcoy, era imprescindible realizar una inspección exhaustiva en los tirantes de este puente, ya que se trataba de una estructura de la misma época, construida cinco años más tarde que el puente de Alcoy, y que utilizaba la misma tecnología de tirantes con cables de acero embebidos en una lechada de cemento y cubiertos con vaina de polietileno.

Los problemas para determinar el estado de los tirantes fueron los mismos que en Alcoy, pero en este caso se vieron 
agravados porque la vaina de protección era doble e impedía el uso de la sonda capacitiva con ciertas garantías para determinar la presencia de huecos en la lechada. Entre otras dificultades, la existencia de aire entre las dos vainas amortigua gravemente la respuesta al cambio de materiales que detecta la sonda

Además, este puente se ve condicionado por un factor muy importante y es el altísimo nivel de tráfico que soporta, más de 100.000 vehículos/día, que hace inviable el corte de tráfico del mismo más allá de unas pocas horas durante la noche.

En otoño de 2016 se realizaron inspecciones en los tirantes del puente del Centenario, orientadas a la detección de eventuales oquedades en puntos críticos de los tirantes, como los coincidentes con las purgas y reinyecciones, habida cuenta de la experiencia adquirida en el puente Fernando Reig, en Alcoy, puente con el que compartía la misma tipología, mismos proveedores de tirantes y equipo constructor. También, con carácter puntual, se levantaron algunos telescópicos para reconocer la eventual presencia de agua o de herrumbre. A pesar de ello los resultados de aquella campaña no fueron del todo concluyentes.

Por todo ello, se realizó una inspección especial exhaustiva, a finales de 2018, consistente en el reconocimiento de los puntos bajos de los tirantes (anclajes inferiores) y en los capots de los anclajes superiores, con objeto de acotar algo más las incertidumbres asociadas al estado de los tirantes del puente. Tales incertidumbres planeaban sobre el puente en la situación actual y también en la fase de sustitución de tirantes, operación delicada y de gran responsabilidad teniendo en cuenta la envergadura del puente y que presenta una clase de consecuencia CC3, en terminología del Eurocódigo 0 EN1990 [3], en caso de accidente.

También se recopiló información acerca de los anclajes superiores en la medida en que ese dato podría condicionar el proceso de retirada de los actuales tirantes, y se incluyeron en la inspección los tirantes de retenida que materializaban el anclaje de los vanos posteriores a las pilas-cimentaciones de acceso.
Como consecuencia de dicha inspección se detectó agua en el tubo de encofrado en 27 anclajes inferiores de los 88 existentes, es decir, aproximadamente en 1 de cada 3 tirantes. Igualmente 41 tirantes evidenciaban discontinuidad de la vaina en la zona previa al anclaje inferior en el tablero, es decir, aproximadamente 1 de cada 2 tirantes. En un gran número de tirantes se evidenciaron deterioros como [13]:

- La existencia de agua al retirar los capots.

- La detección de cordones con alambre central desplazado o deslizado en más del 10\% de los cordones.

- La existencia de agua en el tubo-encofrado.

- La presencia de corrosión en el tubo protuberante de la pieza de anclaje.

- La discontinuidad entre vaina y anclaje, o falta de solape entre ellos.

- La corrosión patente en cordones.

La gravedad y trascendencia de los deterioros, la importancia y ubicación del puente, y los antecedentes del viaducto de Alcoy, llevaron a tomar la decisión de realizar una auscultación del puente en tiempo real y a la redacción, lo antes posible, de un proyecto de sustitución de tirantes.

La necesidad de mantener el tráfico sin apenas restricciones, junto con la imposibilidad de apear el puente, hacía imposible realizar el cambio de los tirantes por los métodos convencionales. Por este motivo ha sido necesario diseñar un nuevo sistema de atirantamiento paralelo al actual por el exterior, junto con unas costillas metálicas inferiores que una vez ejecutado permitirá la retirada de los cables actuales. Además, con este sistema, al desplazarse los tirantes hacia el exterior, la calzada del puente ganará un nuevo carril que mejorará su nivel de servicio.

\subsection{Puente internacional sobre el rio Guadiana}

El puente sobre el río Guadiana fue inaugurado en 1991(figura 9). Su proyecto y construcción se llevó a cabo mediante un

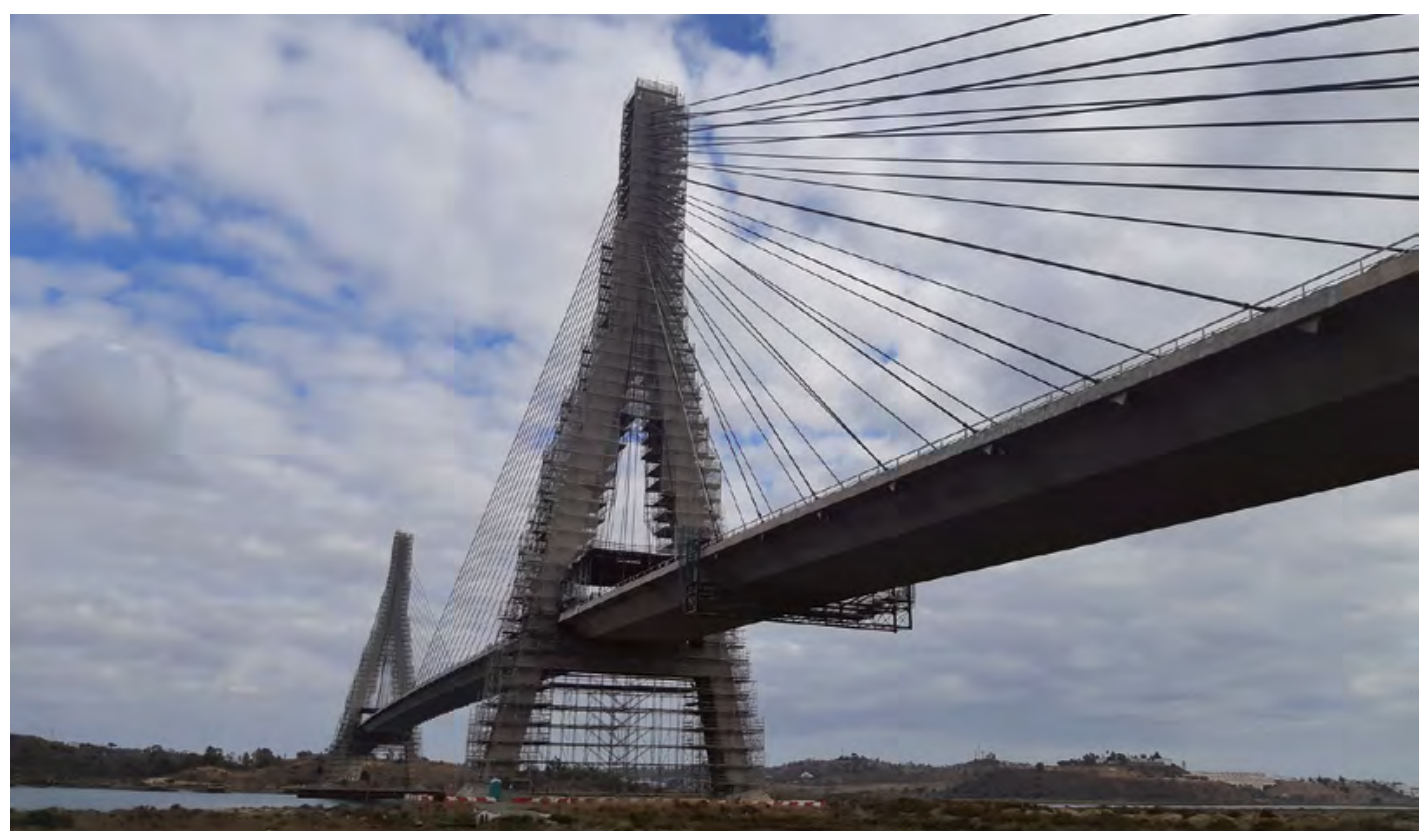

Figura 9. Vista general del puente atirantado sobre el Guadiana con la pasarela bajo tablero. 

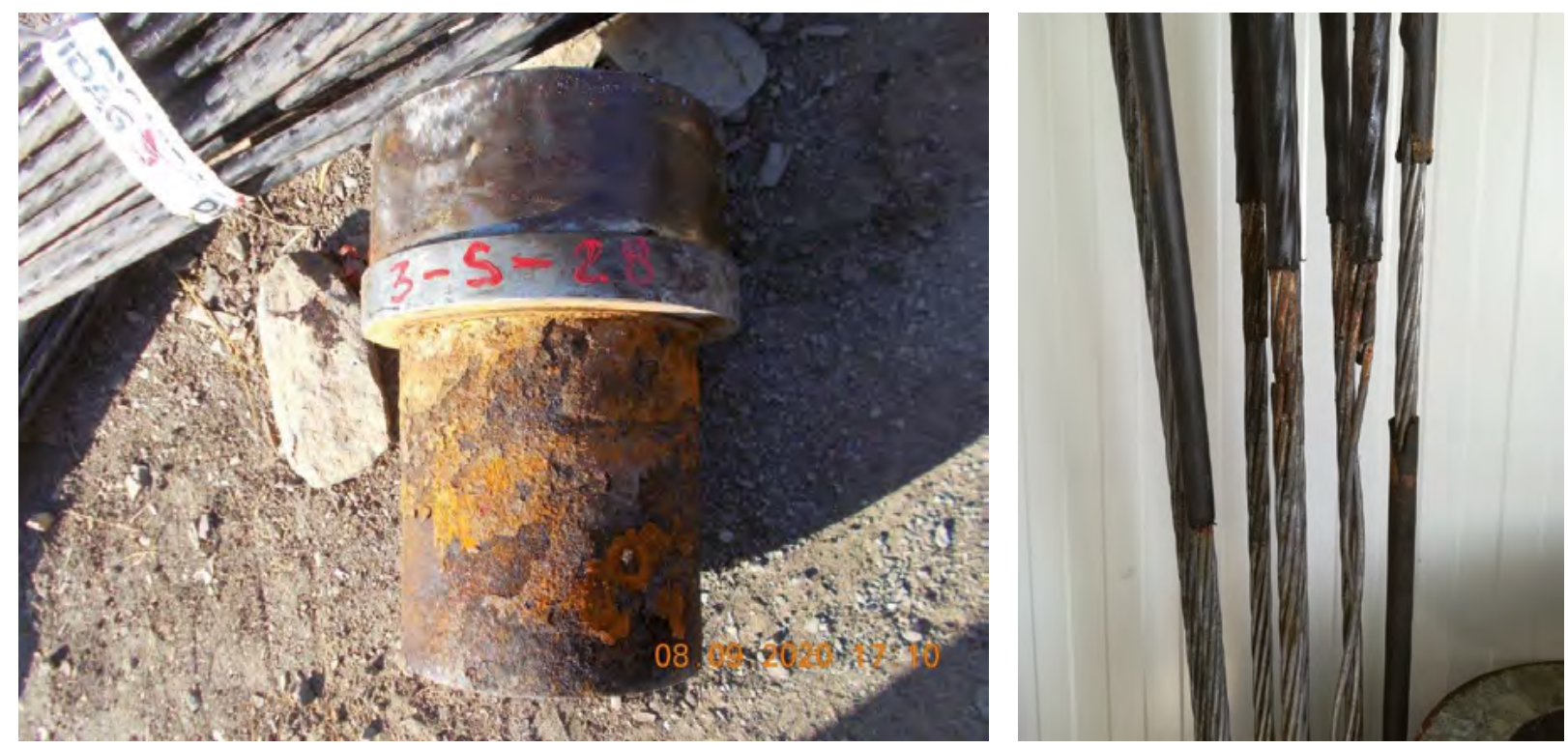

Figura 10. Elementos de anclaje del puente original (izquierda). Estado de los cables de tirantes (derecha).

Convenio entre España y Portugal según el cual la ejecución correspondió a Portugal, obligándose España a pagar la mitad del importe de las obras. El vano central tiene $324 \mathrm{~m}$ de luz, los adyacentes $135 \mathrm{~m}$ y los extremos $36 \mathrm{~m}$. Según lo acordado en la Cumbre de 2002, el mantenimiento de este puente corresponde a Portugal. La Gestión también compete a Portugal, y las obras de rehabilitación extraordinarias serán sufragadas al 50\% por ambos países. Por ello, existe una comisión de seguimiento entre ambos países para supervisar y controlar las actuaciones de mantenimiento realizadas.

A pesar de que es coetáneo con el puente del Centenario, la tecnología del sistema de tirantes es diferente. Esta nueva tecnología se basa en cables autoprotegidos cubiertos de manera individual por un recubrimiento de polietileno que impide que la humedad y otros agentes agresivos alcancen el acero de los cables. Esta tecnología también se diferencia de la anterior porque carece de una vaina global que recoja y proteja todos los cables del tirante. La falta de esta vaina global facilita la inspección y la detección de desperfectos de los cables pero, como se describirá más adelante, genera unos nuevos problemas en la durabilidad de los cordones.

En el año 2008, diecisiete años después de su puesta en servicio, dentro del marco del convenio se acuerda la realización de una inspección detallada de la estructura. En dicha inspección se detecta una serie de deterioros tanto en el sistema de tirantes como en algunos elementos de hormigón, por lo que se procede a realizar un proyecto de rehabilitación.

En 2012 se produjo la rotura de un cordón de uno de los tirantes, siendo necesario su reemplazo. Además de esto, en junio de 2017 se produjo otra rotura, sustituyéndose de inmediato dicho cordón, el cual presentaba problemas de corrosión y pérdida de sección de los hilos a nivel de las extremidades, sobre todo en la parte inferior.

Es importante destacar que la rotura de un cable (del total que constituye cada tirante) no tiene una repercusión estructural muy significativa a corto plazo, pero sí una gran afección sobre la vialidad en el puente, ya que al romperse el cable y no contar con vaina protectora se produce un efecto látigo que puede hacer que el cable impacte sobre los vehículos que transcurren por la plataforma.

Tras la rotura de este segundo cable se consideró necesario realizar una investigación más profunda sobre los problemas de durabilidad presentados. Como resultado de esta investigación se detectó que existían dos mecanismos de deterioro que estaban dañando los cables y provocando su rotura.

El primero es la vibración de los cables. La ausencia de vaina de recubrimiento hace que con cargas muy bajas de viento los cables vibren significativamente, generando movimientos no solo en el conjunto del tirante sino en los cables entre sí. Estos movimientos y choques de los cables dañan su protección y generan pequeñas entallas o desperfectos que por mecanismos de fatiga pueden progresar hasta la rotura de los cordones.

El segundo mecanismo es la corrosión de los elementos de anclaje y del tramo de cable próximo a la cuña de anclaje (figura 10). Este proceso se debe a que las gotas de lluvia o de condensación se deslizan hacia abajo por los cables. Debido a la vibración de los cables antes comentada, ni las "prensa estopas", ni las ceras que recubren los cables en el tramo final, en el que no están recubiertos, tienen la suficiente estanqueidad. Esto hace que la humedad llegue a las cuñas de anclaje y a los tramos de cable sin protección, pudiendo ocasionar, dadas las condiciones locales, una corrosión bajo tensión que provoca la rotura prematura del cable.

El proyecto solo preveía inicialmente la sustitución de 150 cordones de los 4230 existentes en el puente (por estimación del proyectista, dado que no se podía verificar concretamente el estado de los cordones dentro del bloque de anclaje, zona donde ocurrieron las dos roturas de los cordones). En 2015 dicha cantidad fue revisada y aumentó hasta 2500, aproximadamente el $60 \%$ de los existentes.

Tras diversas vicisitudes con la primera adjudicación de la obra (relacionadas con la solvencia del contratista), finalmente en 2018 se contrataron los trabajos de rehabilitación, que está previsto terminen a mediados de 2021.

Después del tiempo transcurrido desde la aprobación del proyecto, y tras los análisis realizados del estado de conserva- 

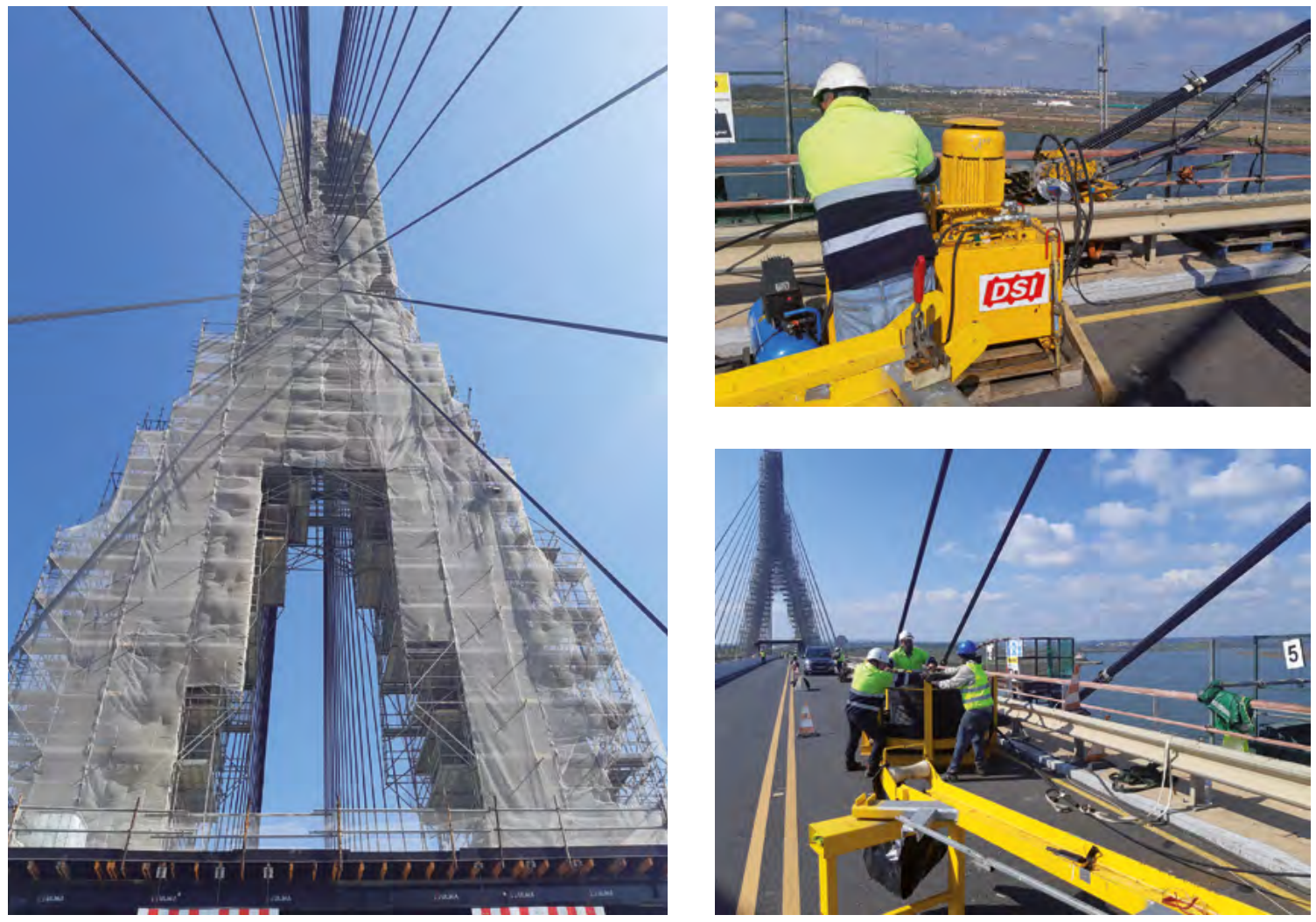

Figura 11. Andamiaje de pilono (izquierda). Sustitución de cables en tirantes y enfilado de cordones (derecha).

ción de los tirantes, la comisión técnica de seguimiento del convenio determinó la necesidad de sustituir todos los cables de los tirantes en lugar del porcentaje establecido en el proyecto.

La sustitución del sistema de tirante en este caso es más sencilla que en los dos anteriores puentes, ya que no hay que sustituir todos los cables del tirante a la vez, sino que se pueden sustituir uno a uno, reduciendo de una manera significativa los medios auxiliares del proceso.

Las obras se están ejecutando actualmente y se están llevando a cabo con el puente abierto al tráfico, aunque con una reducción de carriles, pasando de los cuatro originales (dos por sentido) a dos (uno por sentido), con un tercer carril preparado para ser abierto en caso de emergencia.

\section{6.}

\section{CARACTERÍSTICAS DE LOS NUEVOS SISTEMAS DE TIRANTES INSTALADOS}

La tecnología de tirantes ha avanzado mucho en las últimas décadas para solucionar los problemas de durabilidad que tienen que afrontar, ya que los tirantes están sometidos a diferentes solicitaciones y condicionantes externos a lo largo de su vida útil, como las acciones mecánicas, la fatiga y los esfuerzos o deformaciones excesivas, sobre todo en el transcurso del montaje.

La principal causa de daño en los tirantes es el debido al fenómeno FIP-UIP (fatiga y desgaste inducido por fricción de pequeño movimiento entre los cordones). Además de esto, hay que tener en cuenta las siguientes acciones:
- La corrosión de los cordones, particularmente expuestos a la misma debido a una pequeña relación sección / superficie expuesta a las agresiones.

- Los rayos ultravioletas que degradan las poliolefinas como el polietileno o el polipropileno.

- El calor, que provoca variaciones de temperaturas en los componentes de los tirantes, que pueden conducir a una degradación de las barreras de protección.

- La estanqueidad de los recintos de anclaje inyectados frente a ciclos de temperatura y solicitaciones mecánicas.

- Las acciones locales que pueden llegar a producirse en determinados tirantes por viento, ligadas también a su longitud y amortiguamiento (tema este en estudio).

La concepción de los tirantes actuales incluye barreras y protecciones eficaces para evitar la formación de daños debidos a estas agresiones, tanto en la parte corriente (longitud libre) como en la zona del anclaje [14]. Para ello se dotan de un sistema de triple protección:

- Una vaina exterior que cubre el haz de cordones entre anclajes y aporta una protección global.

- Una doble protección individual en cada cordón.

La vaina exterior de PEAD (polietileno de alta densidad) está concebida para evitar la entrada del agua de lluvia en los tirantes, cuenta con desagües en los puntos bajos para evitar la acumulación de agua proveniente de la condensación, resiste a los rayos ultravioletas en lo que concierne a las poliolefinas y tiene un nervio helicoidal que permite controlar los efectos de inestabilidad aeroelástica provocados por la lluvia y el viento. 
La doble protección individual de los cordones consiste en un recubrimiento de zinc de los hilos del cordón, un material de relleno de intersticios (cera petrolifera) y una vaina individual de PEAD extrusionada sobre la trenza galvanizada y encerada.

Además, para proteger la zona de anclaje, donde el cable pierde su protección individual, se dispone de un dispositivo de impermeabilización local, llamado "prensa-estopa", que permite crear al nivel del anclaje una cámara estanca y protectora rellena por cera petrolera macrocristalina (en fase sólida o líquida).

En las nuevas estructuras que se construyen actualmente, además de esta nueva tecnología estos puentes cuentan con un plan de mantenimiento del sistema de tirantes donde podremos encontrar un cuadro similar a este que se recoge en la tabla 2.

7.

\section{CONCLUSIONES}

Las conclusiones más significativas, dentro de los trabajos efectuados hasta el momento, son las siguientes:

- En los puentes atirantados, las inspecciones básicas y principales no son suficientes. Es preciso realizar inspecciones especiales que permitan caracterizar el estado del sistema de atirantamiento. La periodicidad y alcance de dichas inspecciones deben quedar reflejadas en el plan de mantenimiento que estas estructuras deben tener. Debido a los componentes tecnológicos de este tipo de puentes, es ne- cesario además atenerse a las directrices de conservación que indique el plan de mantenimiento de cada puente, así como a las especificaciones de los fabricantes, que necesariamente han de adaptarse al modo en que se gestiona la infraestructura.

- La DGC realiza inspecciones especiales en los puentes atirantados que gestiona directamente. Esto supone un importante esfuerzo económico y humano. En tres de los más antiguos, puente de Alcoy de 1987, puente del Centenario de 1992 y puente sobre el Guadiana de 1991, la conclusión ha sido sustituir completamente el sistema de atirantamiento, tras unos 30 años de vida en servicio.

- El más antiguo de todos, el puente de Amposta, es un tipo muy singular de puente, de principios del siglo XX, que ha sufrido varias intervenciones importantes, la penúltima en 1972. Sin embargo, tras su inspección, en 2008 se decidió realizar obras de sustitución del sistema de atirantamiento también. Se trata de un puente que cumplirá el año que viene 100 años en servicio.

- Hay que destacar también que la necesaria existencia de sistemas de atirantamientos en estas estructuras conlleva un coste elevado asociado a su conservación e inspección, que ha de tenerse en cuenta durante el estudio tipológico del puente y durante el proyecto.

- Finalmente, queremos ser optimistas, y se exponen algunas características de los nuevos sistemas de tirantes instalados, que nos hacen pensar que su duración será superior a estos 30 años; aportan la ventaja de que al menos será posible sustituir paulatinamente los cables que constituyen los tirantes, de forma planificada. Es necesario, por tanto, prever en los proyectos y en los planes de man-

TABLA 2.

Periodicidad y alcance de las inspecciones del sistema de tirantes: ejemplo

PERIODICIDAD DE INSPECCIONES DEL SISTEMA DE TIRANTES

\begin{tabular}{|c|c|c|}
\hline Alcance de la inspeccion y del mantenimiento rutinario & Periodicidad (meses) & $\begin{array}{c}\% \text { de componentes inspeccionados } / \mathrm{n}^{\circ} \text { total } \\
\text { de tirantes a cada inspeccion }\end{array}$ \\
\hline Parte externa del anclaje inferior & 12 & $25 \%$ \\
\hline Parte intena del anclaje inferior & 60 , con verificacion del sistema de estanqueidad & $10 \%$ \\
\hline Parte externa del anclaje superior & 12 & $25 \%$ \\
\hline Parte intena del anclaje superior & 24 & $25 \%$ \\
\hline Inspeccion simplificada de los tubos al nivel de tablero & 12 & $25 \%$ \\
\hline inspeccion detallada de los tubos al nivel del tablero & 60 & $100 \%$ \\
\hline Inspeccion simplificada exterior del pilono & 12 & $25 \%$ \\
\hline Inspeccion detallada exterior del pilono & 60 & $100 \%$ \\
\hline $\begin{array}{l}\text { Elementos de compactacion de haces de cordones, } \\
\text { centradores, solapes, o conexiones de vainas }\end{array}$ & 60 & $10 \%$ \\
\hline Inspeccion externa de amortiguadores & 60 & $25 \%$ \\
\hline Inspeccion interna y detallada de amortiguadores & $\begin{array}{c}\text { 60, con extraccion de muestras } \\
\text { de componentes amortiguadores desgastables }\end{array}$ & $10 \%$ \\
\hline Limpieza de vaina & N/A, no menor de 120 meses & N/A \\
\hline Sustitucion de un cordon para inspeccion & 1 cada 120 meses & N/A \\
\hline
\end{tabular}


tenimiento estas operaciones de sustitución, con todas las implicaciones que esto conlleva.

\section{8.}

\section{AGRADECIMIENTOS}

Queremos rendir un pequeño homenaje a nuestro compañero Luis Ortega Basagoiti, con el que compartimos muchos momentos en el comité de puentes de la asociación técnica de carreteras, además de entrañables experiencias personales. Luis, uno de los pioneros en patología de estructuras en este país, solía comentar con mucho orgullo su experiencia en la inspección de algunos puentes atirantados, en particular el puente sobre el embalse de Barrios de Luna, en la provincia de León. Por este motivo, pensamos que dedicarle este artículo, en el que se describe la experiencia de los últimos años en inspecciones y obras de rehabilitación de los puentes atirantados existentes en la red de carreteras del estado, que gestiona directamente la Dirección General de Carreteras dependiente del MITMA, hubiera sido de gran agrado para él.

\section{Referencias}

[1] Gonzalez Tascon, I. (2005) Historia del transporte en España. Ed. INECO TIFSA.

[2] Gómez Hermoso, J., Alonso, S., Gonzalez, E., Llor, L.M., Morales, C. (2016) Procesos constructivos 4. Puentes atirantados españoles. 1978-1999. ETSICCP UPM.

[3] AENOR (2003) "Eurocodigos. Bases de calculo de estructuras". (2003) Madrid. (Modificada y completada por EN1990:2003/A, julio 2010).

[4 Comisión Permanente el Hormigón (2008) Instrucción de Hormigón Estructural (EHE-08). Real Decreto 1247/2008.

[5] Comisión Permanente de Estructuras de Acero (2011) Instrucción de Acero Estructural (EAE). Real Decreto 751/2011.

[6] Ministerio de Fomento (2012) Guía para la realización de inspecciones principales de obras de paso de la RCE.

[7] Trotin, N., Ladret, P., Sanchez, J., Vilchez, P. (2017) Mantenimiento y rehabilitación de sistemas de atirantamiento: tecnologías, patologías tipo, inspección, monitorización y reparaciones. VII Congreso de ACHE. Coruña. Junio 2017.

[8] Tabatabai, H. (2005) Inspection and maintenance of bridge stay cable systems: a synthesis of highway practice, NCHRP synthesis, vol. 535

[9] ACHE (2007) Manual de tirantes.

[10] del Pozo, F., Arrieta, J.M., Cerezo, A., et al. (2009) Obras de rehabilitación del puente colgante de Amposta. Hormigón y Acero 60(253).

[11] Mendoza, J., Sanz, C., Prieto, F., León, J. (2016) Informe de Consideraciones sobre la seguridad actual del puente de Alcoy y próximas inspecciones. Documento interno. Fhecor.

[12] León, J. (2016) Informe "Proyecto de reparación de tirantes del puente Fernando Reig, en el PK 794 de la carretera N-340". Documento interno. Fhecor.

[13] León, J., Sánchez, J., Romo, J. (2019) Informe sobre el Puente del Centenario. Inspección especial de los tirantes. Evaluación de su nivel de seguridad. Documento interno. Fhecor.

[14] Apia XXI (2016) Plan de Inspección, Mantenimiento y Conservación del nuevo puente sobre la bahía de Cádiz. Documento interno. 